\title{
Hip and Groin Pain: Physiotherapy and Rehabilitation Issues
}

\author{
Alison Quinn*
}

Sports Surgery Clinic, Santry Demesne, Dublin 9, Ireland

\begin{abstract}
Groin and hip injuries are common in sport. The diagnosis, treatment and rehabilitation of these injuries has long been identified as a complex and challenging area for all clinicians involved in the management of such injuries. While our knowledge increases steadily the challenge still remains for appropriate and successful treatment strategies. Rehabilitation has been identified as an important factor in the management of hip and groin pain. Rehabilitation can occur prior to and after surgery or can be a stand alone treatment for long standing or acute pain. Due to the number and complexity of injuries in the hip and groin area, the physiotherapist must have a strong anatomic and biomechanical knowledge base in order to identify possible aggravating structures or movement abnormalities during the assessment process. Often there is not one single cause for the symptoms but multiple causes. If rehabilitation is appropriate the physiotherapist must put in place a progressively graded rehabilitation programme appropriate to a given sport. There are still gaps in the literature on the provision of the specifics of successful rehabilitation. Therefore the physiotherapist must use sound principles of healing, exercise physiology, manual therapy and rehabilitation, in addition to knowledge of specific stresses and strains that the pelvic area is exposed to within a given sport, in order to provide a successful outcome for the athlete.
\end{abstract}

Keywords: Hip, groin, physiotherapy, rehabilitation.

\section{INTRODUCTION}

\section{Background}

Management of hip and groin injuries in sport continues to be identified as a complex area of clinical diagnosis. This partly arises from the multiple anatomic structures in the hip and groin that are prone to injury [1,2]. Furthermore, signs and symptoms of hip and groin disorders can mimic each other and can be similar to symptoms arising from more distant structures which makes accurate diagnosis difficult.

Appropriate and successful physiotherapeutic and rehabilitative management relies upon precise clinical reasoning and decision making. Functional demands of the presenting sport must be understood in order to plan, guide and progress rehabilitation so that the athlete returns to their optimal level and avoids re-injury.

The purpose of this chapter is to present current concepts in differential diagnosis and assessment of hip and groin injuries in sport which are of particular relevance to physiotherapists. Current evidence on physiotherapy treatment and rehabilitation of these injuries, both as conservative and post surgical management regimes, are discussed. Gaps in the literature and areas for future research are considered.

\section{Incidence of Hip and Groin Injuries in Sport}

Incidence of hip and groin injuries in sport is significant with chronic hip, buttock and groin pain accounting for $10 \%$ of all attendances to sports medicine centres [3]. A $12 \%$

\footnotetext{
*Address correspondence to this author at the Sports Surgery Clinic, Santry Demesne, Dublin 9, Ireland; Tel: +353-1-526-2044; Fax: +353-1-526-2048; E-mail: alisonquinn@sportssurgeryclinic.com
}

incidence of groin and thigh injuries has been reported in football, soccer and ice hockey [4]. Groin injuries alone can account for between $5 \%$ to $18 \%$ of injuries in footballers [5]. A yearly hip injury incidence rate in recreational runners has been reported as being as high as $70 \%[6]$.

Common sports associated with hip and groin injuries are those involving repetitive twisting, kicking and turning movements such as occur in football, soccer, ice hockey, basketball and tennis. In addition, sports that involve running with repetitive impact such as track and field are also affected by these injuries [7].

\section{Risk Factors}

Muscle imbalances have been identified as one of several risk factors for hip and groin injuries in sport. These include greater abductor to adductor strength, core muscle weakness or delayed onset of Transversus Abdominus [8]. Hip flexor weakness has been reported in posterior wall inguinal insufficiency in patients who presented with sports hernia [7]. Hip flexor and abductor weakness and increased adductor strength on the injured side have been found in recreational runners with overuse injuries [9].

Other factors that may contribute to hip and groin injuries in sport include previous injury, sport specific training (both pre-season and during season), incomplete rehabilitation, poor technique, poor running surface or footwear and increased mileage [2, 8]. High intensity, direct impact sports such as hockey or American football can be a risk factor for hip osteoarthritis (OA) [10]. There is conflicting evidence for the role of decreased hip abduction range of motion, adductor strength and length, age and sports experience [8]. If risk factors are identified prevention strategies for hip and groin disorders may be developed through appropriate screening regimes. 


\section{DIFFERENTIAL DIAGNOSIS FOR PHYSIO- THERAPISTS}

There are many causes of hip and groin pain which are extensively referred to in the literature [7, 11-14]. Causes of injuries and disorders include trauma, overuse, muscle strength and length abnormalities, endurance and coordination imbalances across the lumbopelvic region, decreased abdominal stability, inguinal wall weakness and increased shear forces across the hemipelvis. Symptoms may originate from specific local structures (for example adductor tendons, hip joint) or may be referred from other structures (for example, lumbar spine, sacro-iliac joint, neural structures, abdominal viscera, knee joint) or can originate from other pathology (for example, rheumatic disorders). The pathology may be primary in origin or may be secondary due to a history of chronic injury [15]. The variety of structures and potential causes of pain can make differential diagnosis a challenge for the clinician. Table $\mathbf{1}$ summarises some common causes of hip and groin injuries that may present to the physiotherapist.

Physiotherapists may be the first point of contact for patients suffering from many of the conditions listed above. Accurate diagnosis of hip and groin injuries, correct treatment and rehabilitation, and/or appropriate referral as required, avoids long periods of inappropriate treatment. The literature cites examples of incorrect diagnoses. Brannigan et al. describe a $30 \%$ inappropriate referral rate in a group of 127 patients referred for suspected Gilmore's groin [16]. The misdiagnoses included adductor tendon tears and hip osteoarthritis [16]. Byrd and Jones found that $60 \%$ of patients requiring hip arthroscopy surgery were initially given an incorrect diagnosis and patients remained misdiagnosed for between 1 and 114 months [17].

It is beyond the scope of this text to describe all aspects of hip and groin pain, in particular those listed under "Other" in Table 1. However, of particular note for physiotherapists is the references in the literature to soft tissue and joint injury having an origin of systemic inflammatory pathology. Lack of a clear mechanism of injury, progressive symptoms despite modification of activity, in addition to symptoms such as morning stiffness may indicate rheumatic disease such as ankylosing spondylitis, rheumatoid arthritis, gout, pseudogout and less often haemochromatosis and synovial chondrochromatosis [18]. Spondyloarthritis, especially ankylosing spondylitis, can present with enthesitis which can occur at the ischial tuberosities, greater trochanters or iliac

Table 1. Summary of Common Hip and Groin Injuries

\begin{tabular}{|c|c|}
\hline Skeletal & $\begin{array}{l}\text { Fractures e.g. femoral neck and shaft, pelvic } \\
\text { Stress fractures e.g. inferior pubic rami, femoral neck } \\
\text { Avulsions and apophyseal injuries } \\
\text { Hip dislocations and subluxations } \\
\text { Bony bruising }\end{array}$ \\
\hline Articular & $\begin{array}{l}\text { Osteoarthritis of the hip joint } \\
\text { Femoral-Acetabular Impingement (FAI) } \\
\text { Labral tears } \\
\text { Loose bodies in the hip joint } \\
\text { Osteitis pubis } \\
\text { Joint contusions } \\
\text { Intra articular snapping hip }\end{array}$ \\
\hline Soft tissue & $\begin{array}{l}\text { Bursitis } \\
\text { Inguinal hernia } \\
\text { Sports hernia/athletic pubalgia } \\
\text { Snapping hip e.g. Iliotibial band (ITB) or iliopsoas } \\
\text { Capsuloligamentous injury } \\
\text { Muscular contusions e.g. hip pointer } \\
\text { Muscular strains/tendinopathies e.g. quadriceps, hamstrings, abdominals, abductors, adductors, iliopsoas } \\
\text { Piriformis syndrome } \\
\text { Pelvic floor myalgia }\end{array}$ \\
\hline Neural & Nerve entrapment syndromes \\
\hline Referral & $\begin{array}{l}\text { Thoracic spine } \\
\text { Lumbar spine } \\
\text { Sacro-iliac joint }\end{array}$ \\
\hline Developmental & $\begin{array}{l}\text { Perthes disease } \\
\text { Slipped capital epiphysis }\end{array}$ \\
\hline Other & $\begin{array}{l}\text { Rheumatic diseases } \\
\text { Tumours } \\
\text { Infectious diseases e.g. septic arthritis } \\
\text { Intra-abdominal pathology }\end{array}$ \\
\hline
\end{tabular}


crests. Physiotherapists must identify indicative signs and refer on appropriately for medical evaluation.

\section{ASSESSMENT}

The initial physiotherapy consultation for any musculoskeletal injury generally starts with a subjective assessment followed by an objective assessment (or physical examination), an analysis and a plan for treatment [19]. Only relevant topics for the assessment of hip and groin injuries are highlighted in this section. Appropriate questioning followed by accurate physical examination and testing are paramount to begin a successful treatment and rehabilitation programme.

\section{Subjective Examination}

A subjective assessment may include questions on the themes listed below. Further detail of the subjective assessment for hip and groin is provided in other texts $[15$, 20].

- $\quad$ Type of sport - competitive level, main technical aspects of the sport, type of training, any changes in training.

- Detailed history of the condition - mechanism of injury, duration of symptoms, previous successful or failed treatments.

- Past medical history and medication - previous surgery, congenital hip disorders, degenerative joint disease, other medical conditions and red flags (e.g. history of cancer, weight loss, night pain), current medication.

- $\quad$ Aggravating and easing factors.

- $\quad$ Patterns of pain - morning, day time, evening.

- Current functional difficulties encountered by the athlete.

- $\quad$ The athlete's goals for return to sport.

Careful and detailed recording of the location and type of all presenting symptoms in order of severity should be noted on a body chart to highlight the predominant presenting complaint(s). Any symptoms proximal and distal to the main presenting complaint should be noted as pain may be referred from other sources.

Information gained in the history can lead the examiner to an initial working diagnosis and plan for physical examination. Table $\mathbf{2}$ outlines some of the features of common hip and groin complaints that may help identify the cause of pain. This list is not exhaustive. For more detail on discerning pathology and symptoms in the greater trochanter area, the gluteal area and the groin area the reader is recommended to refer to recent texts by Falvey et al., [21] Franklin-Miller et al. [22] and Falvey et al. [23].

\section{Objective Assessment}

Based on information gained in the subjective assessment, the physical examination is planned. The latter must be thorough and systematic to avoid mis-diagnosis [15]. Further detail of the objective assessment for hip and groin is provided in other texts $[5,15,20,27,28]$.

\section{Observation}

The following may be assessed as part of the initial examination: posture in sitting and standing, gait patterns from the frontal and sagital plane, leg length discrepancies by observed or palpated differences in pelvic levels and skin creases, rotational differences between both legs, muscle wasting.

\section{Range of Motion Tests}

Any deviations from normal range of motion or changes in range between left to right side should be noted. Normal range of motion of the hip joint is summarised in Table 3. Range of motion should be assessed in a consistent and reproducible manner e.g. rotation can be measured in the seated position as the pelvis and hip are stabilised, abduction and adduction range can be measured by referencing the shaft of the femur to the midline of the pelvis [15]. Any factors that may limit normal range of motion must be considered which can include capsuloligamentous, muscular or articular causes. These are outlined elsewhere [29].

\section{Palpation}

The exact site of symptoms should be identified by getting the patient to point to the most painful location [15]. Accurate palpation of the symptomatic structure[s] is essential to precisely pin-point structures at fault and to arrive at a diagnosis [21-23]. For example, presence of the $C$ sign usually indicates deep interior pain of the hip joint [15]. Other structures that warrant palpation are the lumbar spine, the sacroiliac joint, pubic symphysis, muscle bellies, lateral aspect of the greater trochanter and trochanteric bursa [15]. Bony pelvic landmarks such as the Anterior Superior Iliac Spine (ASIS), Posterior Superior Iliac Spine (PSIS) and iliac crest should be palpated for symmetry [20]. Circulation can be assessed by palpation of the dorsalis pedis and posterior tibial pulses [15].

\section{Ligament Stress Tests}

Sports that require repetitive rotation e.g. ballet, golf, gymnastics and martial arts may lead to focal rotational laxity or stiffness through microtrauma. The Dial test is described as a test for capsular laxity [15]. However, overall there is a little information in the literature regarding specific stress testing of the capsular and ligamentous structures of the hip joint. This is in contrast to other joints such as the knee and shoulder where ligament stress tests are well described. The hip joint is supported anteriorly by the iliofemoral ligament (also known as the Y-ligament of Bigelow) and pubofemoral ligaments and posteriorly by the iliofemoral and ischiofemoral ligaments. The literature varies somewhat but the consensus appears that the iliofemoral ligament tightens in extension and external rotation, the ischiofemoral ligament tightens in hip internal rotation and adduction (when the hip is flexed) and the pubofemoral ligament tightens in abduction [29-32]. With knowledge of the ligamentous restraints specific ligament tests could be developed.

\section{Muscle Testing}

Manual muscle testing can be used to test the strength of the hip adductors, abductors, hip flexors and extensors, hip 
Table 2. Features of Some Common Hip and Groin Complaints

\begin{tabular}{|c|c|c|}
\hline Disorder & History & Precipitating Sporting Factors \\
\hline FAI [13] & $\begin{array}{l}\text { Insidious onset of groin pain preceded by minor trauma or no } \\
\text { precipitating factor. } \\
\text { Intermittent pain aggravated by physical activities and exercise } \\
\text { or prolonged sitting. } \\
\text { (May be mis-diagnosed as soft tissue injury to the hip or groin). }\end{array}$ & $\begin{array}{l}\text { Sports with flexion/internal rotation e.g. hockey goalkeeping stance, } \\
\text { tennis, martial arts, weight lifting, soccer, horse riding. }\end{array}$ \\
\hline $\begin{array}{l}\text { Labral tears } \\
\quad[13]\end{array}$ & $\begin{array}{l}\text { Deep discomfort in the anterior groin or lateral groin just } \\
\text { proximal to the greater trochanter. } \\
\text { Catching, clicking after a twist or slip injury or subtle pain. } \\
\text { Dull activity induced or positional pain that fails to improve. } \\
\text { (May mimic snapping hip). }\end{array}$ & $\begin{array}{l}\text { Either a repetitive or single cause of high force and extremes of } \\
\text { motion. } \\
\text { Hyper-extension with femoral external rotation can tend to } \\
\text { precipitate the more common anterior labral tear e.g. golf, hockey, } \\
\text { soccer, dancing, gymnastics. } \\
\text { Axial loading with the hip in a flexed position can precipitate the } \\
\text { less common posterior labral tear. }\end{array}$ \\
\hline $\begin{array}{l}\text { Snapping hip } \\
{[13,24]}\end{array}$ & $\begin{array}{l}\text { Pain and audible or perceived snapping of hip during exercise. } \\
\qquad \text { Can be difficult to diagnose. } \\
\text { Can be internal (e.g. iliopsoas), external (e.g. iliotibial band) or } \\
\text { intra-articular (e.g. loose body, labral tear). }\end{array}$ & $\begin{array}{l}\text { External - sudden loading of the hip in a flexed position e.g. landing } \\
\text { from a jump in gymnastics, rebounding in basketball, long jump in } \\
\text { track and field. } \\
\text { Internal - dance, ballet, resistance training (squats), track and field, } \\
\text { uphill running. }\end{array}$ \\
\hline $\begin{array}{l}\text { Sports Hernia } \\
\text { or Gilmore's } \\
\text { groin }[7,16]\end{array}$ & $\begin{array}{c}\text { An exact exacerbating event can be identified or insidious onset. } \\
\text { Four consistent findings - inguinal canal tenderness, dilated } \\
\text { superficial inguinal ring, pubic tubercle tenderness and hip } \\
\text { adductor origin tenderness. } \\
\text { Pain is usually unilateral but can progress to become bilateral. } \\
\text { Aggravating factors include cutting, side steps, sit ups, } \\
\text { coughing, sneezing. } \\
\text { Pain is maximum in the evening or the morning after vigorous } \\
\text { exercise. } \\
\text { Pain eased with rest. } \\
\text { History of failed conservative management. }\end{array}$ & Irish football, soccer, rugby. \\
\hline $\begin{array}{l}\text { Osteitis pubis } \\
{[25]}\end{array}$ & $\begin{array}{l}\text { Pubic symphysis pain and pain into the surrounding areas of the } \\
\text { adductors, abdominal area and hip. } \\
\text { Reason often unknown. }\end{array}$ & $\begin{array}{l}\text { Sports with weighted loading can lead to cyclical loading of pubic } \\
\text { symphysis e.g. running, jumping. }\end{array}$ \\
\hline $\begin{array}{c}\text { Adductor } \\
\text { strains }[25,26]\end{array}$ & $\begin{array}{l}\text { Precipitated by forced hip abduction or vigorous eccentric } \\
\text { contraction. } \\
\text { Tenderness at origin and/or swelling. }\end{array}$ & High kicks and sliding tackles in football, riding, skating. \\
\hline $\begin{array}{c}\text { Iliopsoas } \\
\text { strains }[11,26]\end{array}$ & Poorly localised ache in one side of the groin. & $\begin{array}{l}\text { Forced flexion of the hip against resistance e.g. sit ups, rowing } \\
\text { machine. }\end{array}$ \\
\hline $\begin{array}{l}\text { Stress fractures } \\
{[25]}\end{array}$ & $\begin{array}{l}\text { Common locations include the inferior pubic rami and femoral } \\
\text { neck (the latter is of concern as it can develop into a full fracture } \\
\text { or avascular necrosis). } \\
\text { Worse after running. } \\
\text { Better with rest. }\end{array}$ & $\begin{array}{l}\text { Repetitive cyclical overload of forces caused in pounding activities } \\
\text { such as long distance running. }\end{array}$ \\
\hline $\begin{array}{l}\text { Nerve } \\
\text { compression } \\
{[3,25]}\end{array}$ & $\begin{array}{l}\text { Often non-specific and poorly localised symptoms. } \\
\text { May have cutaneous dermatomal distribution. }\end{array}$ & $\begin{array}{l}\text { Direct trauma in collision sports, clothing compression or } \\
\text { equipment compression e.g. cyclists. }\end{array}$ \\
\hline $\begin{array}{l}\text { Hip } \\
\text { Osteoarthritis } \\
{[10]}\end{array}$ & $\begin{array}{l}\text { Pain in the lateral or anterior hip with weight bearing activities. } \\
\text { Pain may radiate to the anterior thigh and knee. } \\
\text { Morning stiffness. } \\
\text { Limitations in hip range of motion. }\end{array}$ & Direct impact sports e.g. ice hockey, American football. \\
\hline
\end{tabular}

internal and external rotators and knee extensors and flexors [33]. However, the reliability of manual muscle testing has been found to be poor [20]. Functional tests should also be considered for evaluation purposes [8]. These may include squat, lunge, single leg dip and hop tests where control, coordination, endurance and any compensatory movement patterns are assessed. Isokinetic dynamometry testing can be used as an objective measure of hip strength. However further research is needed as there are a limited number of studies which address hip strength using isokinetic dynamometry [34]. Maffey and Emery suggest that further research should address adductor to abductor strength ratios and eccentric testing using isokinetics [8]. 
Table 3. Normal Ranges of Motion of the Hip Joint (Adapted from Neumann, 2002 [29])

\begin{tabular}{|c|c|}
\hline Hip Motion & Range of Motion [Degrees] \\
\hline \hline Flexion & $120[\mathrm{knee}$ flexed $]$ \\
\hline Extension & $20[\mathrm{knee}$ extended] \\
\hline Abduction & 40 \\
\hline Adduction & 25 \\
\hline Internal rotation & 35 \\
\hline External rotation & 45 \\
\hline
\end{tabular}

The author would recommend assessing core stability of the deep abdominal and pelvic muscles at this point in the examination. Initial testing may include positions such as 4 point kneel or bridge [35]. These can be progressed to more challenging positions such as plank, side plank, rotational plank etc as suited to the patient's sport and level of ability.

Muscle length testing of the muscles of the pelvis and thigh include iliopsoas, piriformis, abductors, adductors, extensors, internal and external rotators and knee extensors and flexors and are described elsewhere [19].

A recent article by Malliaras et al. [36] described several reliable hip flexibility and strength measures including bent knee fall out test, hip internal rotation flexibility and the squeeze test, hip external rotation flexibility and hip abduction strength. In the same study hip internal and external strength tests were not found to be reliable.

\section{Neural Tests}

Slump, Prone Knee Bend (PKB) and Straight Leg Raise (SLR) tests can be used to assess neural sensitivity or lumbosacral plexus involvement and are described elsewhere [37]. As the hip joint receives innervation from predominantly L3 of the lumbosacral plexus, hip symptoms may be referred into the L3 dermatome (anterior and medial thigh distal to the level of the knee [15]). Dermatomal, myotomal and reflex testing may also be required. Reflex testing of the quadriceps and Achilles tendons can illicit signs of lumbar radiculopathy [20].

\section{Accessory Movements}

Various accessory movements of the hip, lumbar spine and sacroiliac joint and pelvis can be tested as required [20]. Anterior and posterior glides of the hip joint, superior glide of the pubic symphysis, and anterior and posterior rotation of the ilium are recommended [20]. The reader is referred to other texts for further details of accessory movement testing [38, 39].

\section{Special Tests}

There are many other tests that can be carried out and are described in detail elsewhere $[15,20,36]$.

\section{Leg Length}

There appears to be evidence that leg length inequality can be associated with hip disorders. Friberg [40] suggests that the longer limb may cause chondral damage due to an increased varus position increasing the load bearing surface of the femoral head. Sciatica may occur more on the longer side whereas trochanteric bursitis may occur more on the shorter side. The literature has mixed results on the impact of leg length inequality on symptoms such as hip and low back pain and how much of an inequality is considered clinically significant. Leg length inequalities can be mechanical (a true leg length discrepancy) or functional (due to altered foot biomechanics or soft tissue tightness). A review in 2003 [41] recommended radiography as the most reliable method to check leg length. As this is often not practical or necessary clinically, palpation of pelvic landmarks (with several pelvic landmarks taken such as iliac crests, anterior superior iliac spines, posterior superior iliac spines, and ischial tuborosities) and the use of block correction to evaluate leg length difference yields the strongest support. Although evidence is weak for the use of tape measurement, measuring from the anterior superior iliac spine to the lateral malleolus and using the mean of 2 measurement increases reliability. Clinicians are advised not to correct leg length differences of less than $5 \mathrm{~mm}$ and that lift therapy should be used in incremental steps. Patients should be assessed in different positions to include weight bearing and non-weight bearing e.g. standing, sitting, prone, supine. Clinical practice experience would concur with the difficulties in accurate leg length discrepancy but appropriate heel lifts can have a significant alleviating effect on low back, sacroiliac, hip and groin symptoms. Thoughtful assessment and re-assessment is the key to assess its real relevance in the overall clinical picture.

Following the assessment, an analysis and plan for treatment and rehabilitation can be decided upon. Alleviation of symptoms following treatment techniques confirms if the correct treatment is being applied. If no improvements are being made the patient may require further investigation and/or medical interventions. Timely and appropriate referral avoids unnecessary treatments and potentially hastens the athlete's return to sport. Early diagnosis of pathologies that require surgical intervention has important implications not only for return to sport but also for longer term prognosis. For example correction of labral tears and FAI provides pain relief and may prevent onset OA [13].

\section{REHABILITATION}

The following section describes rehabilitation guidelines for some of the more common conditions outlined in Table 1. Rehabilitation of all conditions are not described but sound diagnosis, clinical reasoning and knowledge the principles of healing, biomechanics and exercise physiology can help the clinician to design a successful rehabilitation programme.

\section{GROIN - TREATMENT AND REHABILITATION}

\section{Conservative Treatment}

A recent review of the effectiveness of exercise therapy in the treatment of groin pain in athletes concluded that exercise therapy is a key factor in rehabilitation [1]. Strengthening of the hip and abdominal muscles were likely to be effective. Exercises should start in static positions and progress to through range and then to functional positions common in the given sport. Concurrent interventions of cardiovascular exercises (e.g. jogging, cycling, running) 
proved a worthwhile adjunct to exercise whereas there was less evidence to support passive treatments and medications. Delivery of exercise interventions for groin pain appeared most effective when delivered in small groups of up to 4 people, all of which were supervised by physiotherapists [1]. Up to 16 weeks was required to complete the exercise programme, highlighting the potentially long treatment times for groin pain which must be impressed on the athlete in terms of managing their expectations for return to sport. Of the five studies examined in the review, strengthening of hip flexors, adductors or abductors and deep or superficial abdominal muscles were highlighted. However, evidence regarding effective intensity and frequency of exercises, resistance or perceived exertion is either unclear or not recorded in the studies. Only one study by Holmich, commonly cited in the literature, provided a reproducible intervention (see Adductor Pain).

Holmich studied long standing groin pain in 207 athletes, mainly football players and runners, and found that adductor related pain in $58 \%$ of the athletes and iliospoas related pain in $35 \%$ of the athletes was the primary clinical entity [5]. Interestingly, only $1.5 \%$ of athletes had sports hernia as a primary clinical entity. $1 \%$ of athletes had rectus abdominus related pain, although this increased to $10 \%$ when secondary and tertiary entities were included. The remaining pathologies responsible for causing groin pain included other pelvic structures such as the sacroiliac joint, hip, piriformis, and pelvic floor. $33 \%$ of patients had co-existing pathologies illustrating the importance of identifying and correcting all relevant dysfunctions in the rehabilitation programme. In contrast, Bradshaw et al. [27], reviewed 218 consecutive cases of longstanding groin pain presenting to a sports medicine clinic and discovered that hip joint pain was the most common presenting complaint [46\%]. Adductor pathology and psoas pathology accounted for $0.5 \%$ and $6 \%$ respectively.

\section{Adductor Pain}

Adductor strains in sport can vary from Grade I to Grade III depending on the level of injury [42]. While any part of the adductor group can be injured (including pectineus, adductor brevis, adductor magnus, gracilis and obturator externus), adductor longus appears to be muscle most frequently injured [42]. The main function of the adductors is open chain adduction and stabilisation of the lower limb in closed chain positions. All adductor muscles can assist in flexion and rotation. As the adductors are stabilisers of the hip joint they are exposed to injury if stabilisation is disturbed through muscle imbalance, muscular fatigue or overload. Mixed results have been reported on the risk factors associated with adductor strains, including decreased abduction [42]. However, it does appear that abduction strength, the ratio of adductor to abductor strength and the presence of a previous adductor strain are risk factors. A ratio of $95 \%$ adductor to abductor strength was shown in injured National Hockey League (NHL) players compared with a ratio of $78 \%$ in injured players [43]. A prevention programme consisting of a warm up, adductor strengthening and sports specific training, with a minimum goal of $80 \%$ adductor to abductor strength, reduced the incidence of adductor strains from $8 \%$ to $2 \%$ compared with the previous 2 seasons [43]. The Adductor Muscle Strain injury prevention programme is shown in Table 4. No specific details were provided on sets, repetitions, frequency or intensity. While this programme is designed for ice hockey players many of the rehabilitation techniques can be easily adapted for other sports. In the same study, those players who did report an adductor strain, a groin strain post injury program was implemented with the main aim being to restore the adduction to abduction muscles strength ratio of the injured limb. This programme is similar to the Adductor Muscle Strain Injury Prevention Programme.

Holmich [44] compared an active training programme with physiotherapy treatment without active training in the treatment of severe adductor related groin pain (athletes had been injured for a median of 9 months prior to the study and $75 \%$ had ceased sporting activity due to pain). It is an important study in that it is a randomised controlled trial and the exercise programme is reproducible, both factors which are generally lacking in the literature. The treatment was carried out 3 times a week in a group format with each training session lasting about 90 minutes. Two exercise modules were used, the first of which was used for the first two weeks. Table 5 illustrates the exercises used in both modules. Module 1 exercises were carried out on the other treatment days by the patient themselves. Following active treatment, $78 \%$ of athletes returned symptom free to their previous level of sport. The median time from entering the study to return to sport was 18.5 weeks (13-26 weeks) again emphasising the long rehabilitation times needed for groin related injuries. The treatment time varied from 8-12 weeks. No adductor stretches were performed or recommended in the active training part of this study and yet the same increase in hip range motion occurred as the non active group who did perform static exercising. Holmich suggested that stretching may worsen the injury by pulling on the insertion at the pubic bone.

Holmich provides the following practical guidelines which can be applied to many rehabilitation programmes [45]:

- Exercise programmes in small classes should be supervised by an instructor, who has also spent time learning the exercise techniques, to ensure the correct method.

- Patients should have therapy sessions 3 to 4 times in the first 2 weeks and then every 10-14 days throughout programme.

- $\quad$ Progress is usually good initially but then slow and progresses again at 6-9 weeks due to the physiological repair process occurring. The athlete must be educated to these facts to ensure compliance to the programme.

- $\quad$ Progress load and repetitions carefully within pain limits. Muscle soreness only is acceptable.

- If there is a failure to respond, other options should be considered for assessment and treatment, e.g. SIJ [sacro-iliac joint] pain, iliopsoas pain, nerve entrapment, hernia etc.

- $\quad$ The programme can be used for acute groin strains once the initial acute inflammatory phase has passed. It can also be used for other clinical entities such as 
Table 4. Adductor Muscle Strain Injury Prevention Programme (Adapted from Tyler et al. 2002 [43])

\begin{tabular}{|l|l|}
\hline Warm up & Bike, stretching adductor muscles, side lunges, sumo squats, pelvic tilt in kneeling \\
\hline Strengthening program & $\begin{array}{l}\text { Ball squeezes, concentric adduction using resistance against gravity, standing adduction using resistance, seated adduction } \\
\text { machine, bilateral adduction using sliding board, lunges with reciprocal arm movements }\end{array}$ \\
\hline Sports specific training & Adduction kneeling on ice, simulated skating using resisted striding, cross over pulls using pulleys, slide skating \\
\hline
\end{tabular}

Table 5. Active Training Programme for Severe Adductor Related Groin Pain (Adapted from Holmich 1999 [44])

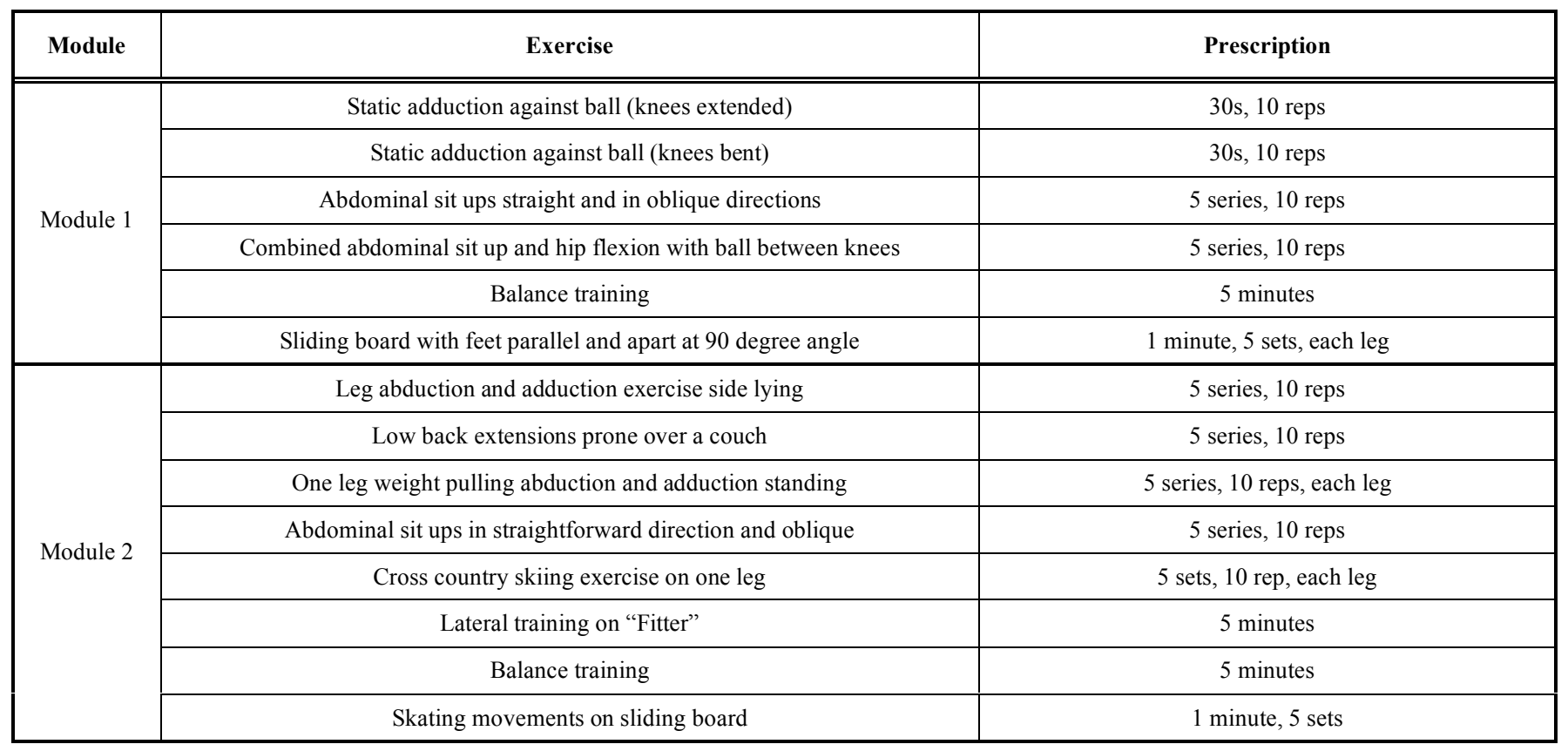

iliopsoas pain, incipient hernia and other pelvis related disorders even though these have not yet been studied.

\section{Iliopsoas Syndrome}

Iliopsoas bursitis and tendinopathy tend to coincide in iliopsoas syndrome [46] (also referred to as snapping hip). Despite the relatively high incidence of this pathology identified in athletes with groin pain, as discussed above, little is written on the topic of its rehabilitation. Treatment of iliopsoas bursitis consists of avoidance of the aggravating activity, stretches into extension for 6 to 8 weeks and hip rotation strengthening (as patients tend to have decreased hip rotation strength) as well as local physiotherapy treatments such as ultrasound [47]. Further referral for injection therapy or surgery can be made if conservative treatment fails. The rehabilitation protocol shown in Table $\mathbf{6}$ has been recommended [46]. Despite the small subject numbers $(n=9)$ the programme appeared to improve pain and facilitated return to full activity.

Stretches to the hip flexors, lateral buttock/piriformis muscles, quadriceps and hamstrings were performed daily. Twice as many stretches were performed on the affected side. No details were provided with respect to stretch times, duration or frequency. No details are given regarding progression to sports specific training.

\section{Osteitis Pubis}

The literature has mixed results on the topic of osteitis pubis as a clinical entity. Holmich agrees with previous research by concluding that osteitis pubis encompasses several different entities and may only rarely be a diagnostic entity in its own right [5]. Jansen et al. concur with this view [48]. Other authors describe osteitis pubis as a clinical entity in its own right $[27,49]$.

\section{Athletic Pubalgia (Sports Hernia, Gilmore's Groin)}

Non-operative treatment for athletic pubalgia, usually consisting of several weeks of rest and graded return to activity, is described as rarely successful [25]. However a recent study by Kachingwe and Grech [20] proposed that conservative management may be a viable treatment approach in the management of athletic pubalgia (the term athletic pubalgia is used due to the usual absence of a hernia in Sports Hernia). There is a general consensus that athletic pubalgia results from injury to the muscular and fascial attachments on the anterior pubis but there is disagreement as to the exact anatomic areas of disruption. Tears may involve all or any of the below mentioned structures:

- Transversalis fascia at the posterior inguinal wall

- Insertion of distal rectus abdominus

- Conjoined tendon at its distal attachment to the anterior superior pubis 
Table 6. Rehabilitation Programme for Iliopsoas Syndrome (Adapted from Johnston et al. 1998 [47])

\begin{tabular}{|c|c|c|}
\hline Stage & Exercise & Prescription \\
\hline \hline Stage 1 (0-2 weeks) & Hip rotation with resistance band in sitting with knees flexed & 3 sets, 20 reps daily \\
\hline Stage 2 (2-4 weeks) & Side lying external rotation and abduction, knees flexed, with resistance band & $\begin{array}{c}3 \text { sets, 20 reps daily (injured side) } \\
2 \text { sets, 20 reps daily (uninjured side) }\end{array}$ \\
\hline & Continue exercises from first stage & $2 / 3$ times per week \\
\hline Stage 3 (4 weeks onwards) & Standing mini-squats with external rotation of opposite leg & $\begin{array}{c}3 \text { sets, 20 reps daily (injured side) } \\
2 \text { sets 20 reps daily (uninjured side) }\end{array}$ \\
\hline & Gait retraining focusing on hip stability using contraction of the deep gluteal \\
& muscles on stance & 10 to 15 steps, 2/3 times day \\
\hline
\end{tabular}

\section{- $\quad$ External oblique aponeurosis}

Operative findings reveal multiple defects in the above structures leading to weakness in the posterior inguinal wall.

Kachingwe and Grech propose the use of an algorithm when athletes present with the 5 signs and symptoms of athletic pubalgia [20]:

- Deep pain in the groin/abdominal area

- $\quad$ Pain aggravated by sports specific activities, such as sprinting, cutting, kicking, and is eased by rest

- $\quad$ Palpable tenderness over the pubic ramus at the rectus femoris and/or conjoined tendon insertion

- $\quad$ Pain on resisted hip adduction at 0, 45 and/or 90 degrees of hip flexion

- $\quad$ Pain on resisted abdominal curl up.

Athletes completed a standardised assessment. Interventions consisted of manual therapy sessions twice a week (soft tissue, joint mobilisations and manual stretching) and supervised rehabilitation with an athletic trainer 3-5 times a week. The rehabilitation programme consisted of dynamic flexibility, core stabilisation and dynamic exercises. All interventions are outlined in detail in the article. The interventions specifically addressed any impairments found in the assessment, for example muscle strength and length deficits, joint hypomobility etc. These sessions continued until the patient returned to pain-free sporting activity. Over an average of 6 weeks, $50 \%$ of the patients returned fully to sport and the remainder underwent surgery. Of the athletes who recovered fully none had an endoscopic examination of their injury to make a definite diagnosis of athletic pubalgia, even though they had the 5 signs and symptoms consistent with a sports hernia and had other pathology out ruled (such as adductor strain, iliopsoas strain, rectus abdominus strain and osteitis pubis). Although subject numbers in this study were small it provides some interesting implications for assessment and treatment of athletic pubalgia. The authors propose that abnormal loads and forces on the anterior pelvis may cause microtrauma to the structures surrounding the pubic symphysis. These may result from several factors including:

- Muscular imbalances, for example, strong hip flexor and adductors in comparison to weak abdominals.

- Movement restrictions, for example, decreased hip extension leading to excessive lumbar spine extension leading to strain on the lower abdominal musculature
- Lower limb and foot malalignment or leg length discrepancies

- $\quad$ One sided dominant sports.

Whatever the cause, the physiotherapist is advised to treat all relevant signs and symptoms regardless of whether the patient receives surgical intervention or not.

\section{Nerve Compression}

Nerve entrapment can cause chronic hip, groin and buttock pain. Although less common than previously mentioned pathologies, the physiotherapist is recommended to be familiar with the neural anatomy, motor innervations and cutaneous sensory distribution around the hip and groin region so that possible causes of neural pain can be identified [3].

Physiotherapists may be more familiar with nerve entrapment syndromes in the upper and lower limb which can cause vague, non-specific symptoms rather than gross neural deficit. Similar symptoms may occur in the pelvic area. While McCrory and Bell [3] note that nerve entrapment syndromes around the pelvis tend to be self-limiting and suggest the use of neuropathic pain medication, injection therapy or surgical intervention for severe cases, Lynch and Renstrom advocate the use of massage to desensitise the area as well as eliminating any sources of compression (e.g. clothing, equipment) as conservative treatment options [25]. While not specifically mentioned in the literature, it is common in physiotherapy practice to use neural mobilisations such as those described by Butler [37] for therapeutic affect and may be relevant for hip and groin nerve irritation.

\section{POST SURGERY MANAGEMENT}

Brannigan et al. [16] reported good symptom and functional improvement following Gilmore's Groin repair on 82 patients mainly having sustained injuries from Irish football and soccer. The mean duration of symptoms was 13.6 months. Of clinical interest, of the 127 patients referred to the clinic with suspected Gilmore's groin, 42 patients were mis-diagnosed and had other pathologies including adductor tendon tears, osteitis pubis and hip osteoarthritis. All patients had failed conservative treatment. 79 out of 85 patients returned to competitive sport within 10 weeks [16]. The authors suggested a post operative rehabilitation protocol which is outlined in Table 7. This was adapted from Gilmore's original protocol [50] by adding 2 weeks to each 
Table 7. Post Operative Rehabilitation Protocol (Adapted from Brannigan and McEntee 2000 [16])

\begin{tabular}{|l|l|}
\hline Weeks 1 -10 & \multicolumn{1}{|c|}{ Exercise Schedule } \\
\hline \hline Weeks 1\&2 & $\begin{array}{l}\text { Walk upright for 20 minutes Day 1 post operation. } \\
\text { Walk gently 4 times per day. } \\
\text { Gentle stretches (e.g. standing toe touch, standing alternating knee to chest). }\end{array}$ \\
\hline Weeks 3\&4 & $\begin{array}{l}\text { Walk for 30 minutes 4 times per day for 4 days. } \\
\text { Jog and run gently for the next 3 days. }\end{array}$ \\
\hline Weeks 5\&6 & $\begin{array}{l}\text { Run in straight lines. } \\
\text { Gentle sit-ups. } \\
\text { Adductor exercises (e.g. adduction in sitting against resistance). }\end{array}$ \\
\hline Weeks 7\&8 & $\begin{array}{l}\text { Sprint in straight lines. } \\
\text { Increase the number of sit ups. } \\
\text { Begin front crawl swimming. }\end{array}$ \\
\hline Weeks 9\&10 & Return to sport. \\
\hline
\end{tabular}

stage as the patients had a lower level of fitness than Gilmore's cohort of patients. Despite trunk rotation and hyperextension being noted as causative factors the post surgery rehabilitation protocol does not address these issues.

\section{HIP - TREAMENT AND REHABILITATION}

\section{Conservative Treatment}

\section{Soft Tissue Injury}

There is less information in the literature describing specific rehabilitative protocols for hip injures. This may be because the majority of athletic injuries to the hip involve soft tissue damage [51] which may be more straightforward to manage and rehabilitate than some of the groin pathology discussed earlier. Examples of soft tissue injury include muscle strains, bursal damage, contusions and capsuloligamentous injury. Injuries can be caused by a direct blow or by fast, high velocity, often eccentric contractions. General guidelines provided by Konin and colleagues [51] for the management of soft tissue injuries include soft tissue mobilisation, stretching, frictions, proprioceptive neuromuscular facilitation (PNF) techniques, compression wraps, cryotherapy, electrical stimulation and hold relax techniques. Local and global strengthening including rotational and eccentric strengthening is also recommended. While stiffness and laxity of capsuloligamentous structures through repetitive motion has been highlighted previously no treatment is described for these injuries. Treatment techniques such as soft tissue or joint mobilisations are common in capsuloligamentous structures of other joints such as the knee, ankle or shoulder and one would postulate that similar techniques may have therapeutic affect for the hip joint. The physiotherapist should screen for myositis ossificans when assessing soft tissue injuries.

\section{FAI, Labral Tears and Snapping Hip}

With the increase of hip arthroscopy, three more recently described causes of hip pain include FAI, labral tears and snapping hip. Many of these presentations will require surgery, the descriptions of which are beyond the scope of this chapter. Initial treatment for FAI may involve a trial period of conservative treatment consisting of activity modification, particularly a decrease in excessive end of range movements, with appropriate medication and analgesia, technique modification and associated muscle balance work [52]. Many athletes will go on to have surgical treatment. Labral tears are treated surgically and some cases of snapping hip are treated surgically and are described elsewhere [13].

\section{Osteoarthritis}

A significant source of pain in the hip is due to osteoarthritis (OA) which is becoming more common in younger populations. Since 1990, the age group that has seen the greatest increase in Total Hip Arthroplasty (THA) is those aged between 45-64 years [53]. A comprehensive review and clinical practice guidelines for hip OA is detailed by Cibulka et al. [10]. A summary of the recommendations from this review is found in Table 8. The purpose of the guidelines was to create evidence based guidelines for physiotherapy management of patients with osteoarthritis.

While manual therapy, flexibility, strengthening and endurance programs are recommended no specific details are recommended on intensity, frequency, duration, rating of perceived exertion or exercise details. Many patients with moderate or severe hip OA will undergo surgical intervention and will require rehabilitation post surgery which is discussed in the following section.

\section{POST SURGERY MANAGEMENT}

\section{Arthroscopy}

The increase in hip arthroscopy techniques has required appropriate rehabilitation protocols, the details of which vary in the literature. Protocol guidelines will vary depending on surgeon requirements, type of surgery, medical status of the patient etc. Clinical reasoning must take account of soft tissue healing, swelling, early range of motion, limitations of weight bearing, early initiation of neuromuscular activity, progressive strength and proprioceptive training, cardiovascular training and sport specific training. The aim of rehabilitation post arthroscopic surgery is to return the patient back to their pre-injury level of activity and in the case of the athlete to the pre-injury level of competition [54]. Stalzer et al. [54] describe 4 phases of rehabilitation post hip 
Table 8. A Summary of Recommendations For Hip Pain and Mobility Deficits in Hip Osteoarthritis (Adapted from Cibulka et al. $2009[10])$

\begin{tabular}{|c|c|c|}
\hline Factor & Recommendations & Evidence Base \\
\hline Patho-anatomy & Mobility and strength of the hip, particularly the hip abductor muscles should be assessed. & Weak \\
\hline Diagnosis & $\begin{array}{l}\text { Moderate lateral or anterior hip pain during weight bearing (in adults greater than } 50 \text { years) } \\
\text { with morning stiffness of less than } 1 \text { hour with limited hip flexion and internal rotation by } \\
\text { more than } 15 \text { degrees on the painful side. }\end{array}$ & Strong \\
\hline Examination/outcome measures & $\begin{array}{l}\text { Validated functional outcome measures before and after interventions should be used such as } \\
\text { Western Ontario and McMaster Universities Osteoarthritic Index, Lower Extremity } \\
\text { Functional Scale and Harris Hip Score. }\end{array}$ & Strong \\
\hline $\begin{array}{l}\text { Examination - activity limitation and } \\
\text { participation restriction measures }\end{array}$ & $\begin{array}{l}\text { Easily reproducible examination measures should be used - for example - 6-minute walk, } \\
\text { self paced walk, stair measure, timed up and go tests. }\end{array}$ & Moderate \\
\hline Interventions - manual therapy & $\begin{array}{l}\text { Manual therapy may be used for short term pain relief and improvement of hip mobility and } \\
\text { function in patients with mild OA. }\end{array}$ & Moderate \\
\hline $\begin{array}{l}\text { Interventions - flexibility, } \\
\text { strengthening and endurance } \\
\text { exercises }\end{array}$ & Strength, flexibility and endurance exercises should be used in patients with OA. & Moderate \\
\hline
\end{tabular}

arthroscopy - initial, intermediate, advanced and sportspecific training. They recommend that all patients adhere to this common rehabilitation programme but provide variations to the programme depending on the type of surgery performed e.g. labral repair, osteoplasty, microfracture, capsular repair. The patient progresses through each phase once they have fulfilled certain criteria. Phase 1 is started immediately post surgery, phase II occurs at about 4-6 weeks, Phase III at 6-8 weeks and phase IV at 816 weeks. A summary of the phases is outlined in Table 9. Specific precautions and alterations to the guidelines are provided for different surgeries and the reader is referred to the text for more detail on the precautions and exercises used in the rehabilitation guidelines. Rehabilitation guidelines are outlined by other authors $[55,56]$ which divide rehabilitation into similar phases and provide different rehabilitation requirements for different arthroscopic techniques. The guidelines for rehabilitation generally do not provide guidance on repetitions, duration or intensity of exercise. Further research is needed to devise evidence based protocols post arthroscopic interventions.

Philloppon et al. [55] describes the use of pre-operative baseline clinical, special tests and functional tests prior to surgery. These include range of motion testing and isometric hip muscle strength testing. Special tests include anterior impingement, posterior impingement, abduction impingement, Obers, Dial (log roll) and FABER tests. A functional sport cord was used to test agility. Pre-operative testing allows both objective and subjective data pre and post surgery to be compared and helps to more fully quantify patient outcomes.

\section{Arthroplasty}

Candidates for THA procedures are usually more than 60 years old. Younger patients elect this surgery when their functional status is severely compromised and their pain becomes intolerable. THA improves function and reduces pain in virtually all patients with the disabling disease.

Current data shows that the average patient stay in hospital is decreasing. Shorter in-patient stays decrease the time available for physical recuperation, inpatient rehabilitation and patient and family education. However it allows increased emphasis on out-patient services such as pre-operative education and out-patient physiotherapy intervention $[57,58]$.

Postoperative rehabilitation after THR requires a degree of flexibility as rehabilitation protocols may depend on issues such as the surgical approach used (posterolateral, anterolateral, direct anterior) and whether a cemented or noncemented implant is used. It is important to be aware of the surgical procedure and implant type in order to guide a patient through a rehabilitation protocol safely and successfully [59].

Studies recommend that patients who have undergone THA should continue to undertake a therapeutic exercise program for at least a year and be given a more advanced exercise program later in their recovery [60-62]. There are however no evidence-based guidelines to direct best practice for post-acute rehabilitation following THA [57]. Generally protocols are based on clinical experience and surgeon 
Table 9. Rehabilitation Following Hip Arthroscopy (Adapted from Stalzer et al. 2006 [54])

\begin{tabular}{|c|c|c|}
\hline \multirow[t]{3}{*}{$\begin{array}{l}\text { Phase I } \\
\text { Immediate } \\
\text { Rehabilitation }\end{array}$} & Goals & $\begin{array}{l}\text { Protect the repaired tissue } \\
\text { Restore Range of Motion (ROM) within any restrictions } \\
\text { Decrease pain and swelling } \\
\text { Prevent muscular inhibition }\end{array}$ \\
\hline & Precautions & $\begin{array}{l}\text { Avoid push through hip flexor pain } \\
\text { Specific ROM restrictions (surgery dependent) } \\
\text { Weight-bearing restrictions }\end{array}$ \\
\hline & Criteria for progression to Phase II & $\begin{array}{l}\text { Minimal pain with exercises } \\
\text { ROM greater than or equal to } 75 \% \text { of the uninvolved side } \\
\text { Correct muscle firing patterns } \\
\text { Progress to next phase when fully weight bearing }\end{array}$ \\
\hline \multirow[t]{3}{*}{$\begin{array}{l}\text { Phase II } \\
\text { Intermediate } \\
\text { Rehabilitation }\end{array}$} & Goals & $\begin{array}{l}\text { Protect the repaired tissue } \\
\text { Restore full ROM and normal gait } \\
\text { Gradually increase muscle strength }\end{array}$ \\
\hline & Precautions & $\begin{array}{l}\text { Avoid ballistic or forced stretching } \\
\text { Avoid treadmill } \\
\text { Avoid hip flexor or joint inflammation }\end{array}$ \\
\hline & Criteria for progression to Phase III & $\begin{array}{l}\text { Full ROM } \\
\text { Pain free and normal gait } \\
\text { Hip flexion strength greater than } 60 \% \text { of the uninvolved side } \\
\text { Hip adduction, abduction, extension, internal and external rotation strength }>70 \% \text { of } \\
\text { the uninvolved side }\end{array}$ \\
\hline \multirow[t]{3}{*}{$\begin{array}{l}\text { Phase III } \\
\text { Advanced }\end{array}$} & Goals & $\begin{array}{l}\text { Restore muscular endurance/ strength and cardiovascular endurance } \\
\text { Optimize balance and proprioception }\end{array}$ \\
\hline & Precautions & $\begin{array}{l}\text { Avoid hip flexor/joint inflammation } \\
\text { Avoid ballistic or forced stretching/strengthening } \\
\text { Avoid treadmill } \\
\text { Avoid contact in sport }\end{array}$ \\
\hline & Criteria for progression to Phase IV & $\begin{array}{l}\text { Hip flexion strength greater than } 70 \% \text { of the uninvolved side } \\
\text { Hip adduction, abduction, extension, internal and external strength greater than } 80 \% \text { of } \\
\text { the uninvolved side } \\
\text { Return to previous cardiovascular fitness } \\
\text { Start agility drills with correct patterning }\end{array}$ \\
\hline $\begin{array}{l}\text { Phase IV } \\
\text { Sports Specific Training }\end{array}$ & $\begin{array}{l}\text { Criteria for Full Return to } \\
\text { Competition }\end{array}$ & $\begin{array}{l}\text { Full and pain free ROM } \\
\text { Hip strength greater than } 85 \% \text { of the uninvolved side } \\
\text { Return to pain free sport-specific drills at full speed } \\
\text { Complete functional sports test }\end{array}$ \\
\hline
\end{tabular}

preference $[59,63]$. Westby et al. also notes that there are no systematic long term follow up in terms of functional ability and surgical outcome [57].

Improved surgical techniques and implants are allowing increased activities to be undertaken following THA. However, few validated guidelines exist for return to sport after THA. Those patients who are athletically inclined need greater input and follow up in order to address the balance between return to activity and return to too much activity. Load and risk is less in the recreational rather than peak fitness athlete and therefore return to levels of activity in the latter may have to be modified. High impact activities such as squash, snowboarding, high impact aerobics and jogging are not advocated by surgeons [53, 64]. Alternatives included closed chain lower impact activities such as power walking, hiking, biking, swimming, and various gym activities including stair climber and cross trainer. High contact sports such as football and rugby should be avoided. Rehabilitation programs for the athlete wishing to return to activity should be tailored for the patient's requirements and adequate strength must be achieved before return to activity. Hip abductor weakness is particularly important as abductor strength is thought to improve by $50 \% 6$ months after THA [53]. The intensity of activity that the patient returns to is dependent on their previous level of skill e.g. skiing, weight lifting. Routine radiographs are recommended in higher athletic populations. Return to athletic activity is recommended between 3 and 6 months [53]. 


\section{PREHABILITATION PRIOR TO SURGERY}

While research on pre-habilitation is sparse, it is recommended in order to maximise function prior to surgery, explain the rehabilitation process post surgery and identify patients who may not be compliant [56]. In a recent systematic review, Sharma and colleagues [65] suggested that preoperative physiotherapy may promote faster recovery post operatively. However further research is needed to confirm this finding. Rooks et al. [66] reported on a preoperative exercise program 3 times a week for 6 weeks prior to total knee and hip replacements. The programme consisted of a general cardiovascular, strengthening and flexibility programme, both water and land based. The THA group improved their strength and functional scores prior to surgery. Patients reported that they were more physically and mentally prepared for the surgery. Patients dramatically reduced the odds of discharge to a rehabilitation facility by $73 \%$ which provided economical benefits. There is a need for research to ascertain if specific exercises prior to surgery can further improve outcome measures and discharge status. This would have important implications for the athlete whose timely return to optimal performance is paramount.

\section{OTHER ASPECTS OF PHYSIOTHERAPY TREAT- MENT AND REHABILIATION}

\section{Treatment of the Sacro-Iliac Joint in Hip and Groin Pain}

Cibulka and Delitto recommended that the Sacroiliac Joint [SIJ] be assessed in patients with hip pain [67]. SIJ dysfunction can be confirmed by the presence of three out of four tests - standing flexion, uneven posterior superior iliac spines, supine long sitting and prone knee flexion. SIJ manipulation or using long axis distraction mobilisation techniques can be an effective way to reduce hip pain [67]. It is theorised that manual therapy may alter muscles forces around the hip joint or change the hip joint congruence by changing hip joint obliquity. In the author's experience appropriate manual treatment techniques applied to the SIJ can improve hip and groin pain, increase range of motion and decrease symptoms.

\section{Hip Rehabilitation Exercises}

Hip extension and abduction exercises are often used in the rehabilitation of hip and back pathologies. Gluteus maximus and minimus are important in the role of frontal stability of the pelvis and should work synergistically rather than in isolation in assessment and rehabilitation of frontal plane stability of the injured athlete [68]. Jae-seop et al. [69] demonstrated that the amplitude of gluteus maximus contraction increased by performing an abdominal drawing in manoeuvre. In addition the amplitude of erector spinae contraction decreased and the angle of anterior pelvic tilt decreased. Use of a pressure biofeedback unit was recommended to recruit the abdominal drawing in manoeuvre. Clinical practice shows that patients can excessively extend their lumbar spine and anterior tilt their pelvis during hip extension. Appropriate correction by the therapist can increase the efficiency of the gluteus maximus contraction and avoid excessive shear forces on the lumbar spine.

Six abduction exercises were investigated by Bolga and Timothy [70]. EMG analysis of gluteus medius activity was performed in three weight bearing exercises (standing pelvic drop, weight bearing hip abduction, weight bearing hip abduction in a flexed position) and three non-weight bearing exercises (side lying hip abduction, non-weight bearing standing hip abduction, non-weight bearing flexed standing hip abduction). Baseline EMG analysis revealed that weight bearing exercises and the non weight bearing side lying abduction exercise yielded higher EMG amplitudes than the non-weight bearing hip abduction and hip abduction/flexion exercises. The latter exercises were therefore recommended for those patients early in the rehabilitation process depending on their level of strength. Patients should progress to non-weight bearing side lying exercises if their weight bearing status is compromised but eventually should progress to more functional weight bearing exercises. Weight bearing abduction and flexion is preferable due to its functional position for sport. Pelvic drop requires even more control. In all weight bearing exercises it is important for the therapist to monitor trunk position.

Control of lower extremity motion in the frontal and transverse planes is thought to contribute to lower limb injury. In a recent study by Snyder et al. [71], a hip abductor and external rotation strengthening programme not only strengthened the muscles involved but also led to alteration of lower extremity joint loading during running by reducing the range of ankle eversion, reducing the range of hip internal rotation and reducing knee abduction and rearfoot inversion moments. Three closed chain exercises were performed three times a week for 6 weeks using the principles of one repetition maximum and progressive overload. Closed chain exercises were chosen as they are more functional and require increased neuromuscular coordination. While the study numbers were low $(n=15)$ the results are interesting in that they suggest that hip strengthening affects knee and rearfoot mechanics and should be considered as part of a rehabilitation programme. Lower limb mechanics are often corrected by altering foot position using orthoses. This study offers an alternative or at least a concurrent way of affecting foot motion. In addition, external rotation in combination with abduction is chosen as the exercise of choice. Little is mentioned in the literature regarding strengthening of the hip rotators.

\section{Role of the Stabilising Muscles}

Physiotherapy and rehabilitation literature has references to the role of the stabilising muscles in injury prevention particularly in low back pain $[72,73]$. It is thought that the more powerful propulsive muscles can act more efficiently when the stabilising muscles are working efficiently. The stabilising muscles include transversus abdominus, pelvic floor, diaphragm, multifidus and the oblique abdominals. The hip abductors and adductors may work more explosively when the stabilising muscles are working efficiently. A delay of transversus abdominus has been shown in adductor related groin pain in Australian Rule Football players [74]. Rugby Union players showed fewer injuries following a Swiss ball stability programme [75].

\section{Manual Therapy}

Manual therapy forms a core component of physiotherapeutic intervention. Mokofsky et al. [76] found a statistically significant increase in abductor torque in a group of healthy 
subjects when a grade IV inferior hip joint mobilisation at 45 degrees of abduction was performed $(17.35 \%$ compared to $3.68 \%$ for the control group). Three repetitions of one minute of mobilisation with a 30 second rest between repetitions were used. Yerys et al. [77] showed that a Grade IV mobilisation of the anterior hip capsule yielded a significant increase in gluteus maximus strength. Three Grade IV mobilisations performed for 1 minute each with a 30 s rest caused a 14 fold increase in muscle strength. It is assumed that mobilisation of the restricted capsuloligamentous tissue of the hip capsule may allow the hip abductors and extensors to function more effectively through the full range. The arthrokinematic reflex of joint mechanoreceptors afferents may affect periarticular muscle tone. Greater success in achieving strength gains may be achieved with manual therapy prior to strengthening.

Wong and Schauer-Alvarez [78] found that strain counterstrain techniques (positional release) used on tender points reduced pain and positively affected strength. 90 second holds were used. The mechanics by which strength gains occur may be through neural factors or a motor learning effect. Strength increased by up to $60 \%$ and strength increases lasted for 2-4 weeks post technique. Clinical practice shows that soft tissue manipulation increases manual strength and ROM.

\section{Flexibility}

Regular stretching has been shown to reduce the risk of injury and some aspects of performance [79]. The relevance of specific stretching programmes in hip and groin injuries is unclear. While there is conflicting evidence over the use of adductor length as a risk factor for groin injury [7], it appsears that reduced hip internal and external rotation may be a factor in developing groin pain [80]. It may be more appropriate to prescribe stretching programmes based on the relevance of the findings on full examination, the demands of the sport and the individual playing that sport [8].

\section{CONCLUSION}

Physiotherapy treatment and rehabilitation of hip and groin injuries continues to present a clinical challenge. While the clinical knowledge base grows there are still gaps in our understanding of the diagnosis and treatment of disorders in this area. There continues to be lack of agreement on the definition of and diagnostic criteria used in hip and groin injuries. Differential diagnosis is complex and multiple clinical entities often co-exist. There is a lack of methodical assessment and reliable examination methods $[5,7]$.

Exercise appears to be an important part of rehabilitation in both conservative and post surgical hip and groin disorders. However, conservative exercise interventions are poorly described. Broad rehabilitation guidelines exist but in general they are not reproducible. There is a lack of high level, high quality primary evidence [1].

Further clarification is required on the specifics of exercise prescription in terms of duration, frequency, intensity and progression of same. Future research could address the use of eccentric testing and rehabilitation programmes, flexibility programmes, sport specific programmes and proprioceptive/balance programmes.
While we continue to explore hip and groin disorders, physiotherapists are well placed to analyse and identify movement dysfunction and assign appropriate rehabilitation strategies both in individual and group settings. The role of the physiotherapist is firstly to decide which presentations are appropriate for conservative treatment and which require appropriate referral and further investigations. Early diagnosis can have important implications particularly for the athlete as further symptoms and inappropriate treatments can be avoided. For those that require conservative treatment it may not be necessary to identify one or more key specific faults but to treat all relevant symptomatic faults in a progressively graded functional and sports specific manner using the basic principles of anatomy, biomechanics and muscle physiology. The athlete should be made fully aware of the planned duration of rehabilitation and realistic timescales for return to sport, which in some cases can be up to several months, so that appropriate healing and effective return to sport can be maximised.

\section{REFERENCES}

[1] Machotka Z, Kumar S, Perraton LG. A systematic review of the literature on the effectiveness of exercise therapy for groin pain in athletes.Sports Med Arthrosc Rehabil Ther Technol [serial on the internet]. 2009 March 31; 1(5]: [About 10 screens].Available from http://www.ncbi.nlm.nih.gov/pubmed/19331695.

[2] Paluska SA. An overview of hip injuries in running. Sports Med 2005; 35 (11): 991-1014.

[3] McCrory P, Bell S. Nerve entrapment syndromes as a cause of pain in the hip, groin and buttock. Sports Med 1999; 27 (4): 261-74.

[4] Simonet WT. Injuries of the thigh and groin. Sideline View 1987; 9 (2): 1-4.

[5] Holmich P. Long-standing groin pain in sportspeople falls into three primary patterns, a "clinical entity" approach: a prospective study of 207 patients. Br J Sports Med 2007; 41: 247-52.

[6] Van Mechelen W. Running injuries: a review of the epidemiological literature. Sports Med 1992; 36 (5): 320-35.

[7] Caudill P, Nyland J, Smith C, Yerasimides J, Lach J. Sports hernias: a systematic literature review. Br J Sports Med 2008; 42: 954-64.

[8] Maffey L, Emery C. What are the risk factors for groin strain injury in sport? A systematic review of the literature. Sports Med 2007; 37(10): 881-94.

[9] Niemuth TJ, Johnson PE, Myers RJ, Thieman MJ. Hip muscle weakness and overuse injuries in recreational runners. Clin J Sports Med 2005; 15(1): 14-21.

[10] Cibulka MT, White DM, Woehrle J, et al. Hip pain and mobility deficits - hip osteoarthritis: clinical practice guidelines linked to the International Classification of Functionning, Disability, and Health from the Orthopaedic Section of the American Physical Therapy Association. J Orthop Sports Phys Ther 2009; 39(4): A1-A25.

[11] Bruker P, Khan K. Clinical Sports Medicine. 3rd ed. Sydney: McGraw-Hill 2006.

[12] Anderson K, Strickland SM, Warren R. Hip and groin injuries in athletes. Am J Sports Med 2001; 29 (4): 521-33.

[13] Blankenbaker MJ, TuiteDG. The painful hip:new concepts. Skeletal Radiol 2006; 35: 352-70.

[14] Zulaga M, Briggs C, Carlisle J, et al., Eds. Sports Physiotherapy Applied Science and Practice. Melbourne : Churchill Livingstone 1998.

[15] Domb BG, Brooks AG, Byrd JW. Clinical examination of the hip joint in athletes. J Sport Rehab 2009; 18: 3-23.

[16] Brannigan GP, Kerin AE, McEntee MJ. Gilmore's groin repair in athletes. J Orthop Sports Phys Ther 2000; 30 (6): 329-32.

[17] Byrd K, Jones T. Hip arthroscopy in athletes. Clin Sports Med 2001; 20 (4): 749-61.

[18] Jennings F, Lambert E, Fredericson M. Rheumatic diseases presenting as sports-related injuries. Sports Med 2008; 38 (11): 917-30.

[19] Petty N, Neuromuscular examination and assessment. A Handbook for Therpaists. $2^{\text {nd }}$ ed. Melbourne: Churchill Livingstone 2005. 
[20] Kachingwe A, Grech S. Proposed algorithm for the management of athletes with athletic pubalgia [Sports Hernia]: a case series. J Orthop Sports Phys Ther 2008; 38 (12): 768-80.

[21] Falvey EC, Franklyn-Miller A, McCrory PR.The greater trochanter triangle; a pathoanatomic approach to the diagnosis of chronic, proximal, lateral, lower pain in athletes. Br J Sports Med 2009; 43: $146-52$.

[22] Franklin-Miller A, Falvey E, McCrory P. The gluteal triangle: a clinical patho-anatomical approach to the diagnosis of gluteal pain in athletes. Br J Sports Med 2009; 43: 460-6.

[23] Falvey EC, Franklyn-Miller A, McCrory PR. The groin triangle: a patho-anatomical approach to the diagnosis of chronic groin pain in athletes. Br J Sports Med 2009; 43: 213-20.

[24] Garry J, Jenkins WL. Snapping Hip Syndrome. emedicine from WEBMD [serial on the internet]. 2006; [about 3 screens]. Available from: http:/emedicine.medscape.com/article/87654overview.

[25] Lynch SA, Renstrom PAFH. Groin injuries in sport. Treatment Strategies. Sports Med 1999; 28 (2): 137-44.

[26] Whyte GD, Harries M, Williams C, Eds. ABC of Sports and Exercise Medicine. 3rd ed. Oxford: Wiley 2005.

[27] Bradshaw CJ, Bundy M. Falvey E. The diagnosis of longstanding groin pain: a prosepctive clinical cohort study. Br J Sports Med 2008; 42: 851-4

[28] Braly BA, Beall DP, Martin HD. Clinical examination of the athletic hip. Clin Sports Med. 2006; 25 (2): 199-210.

[29] Neumann D. Kinesiology of the Musculoskeletal System. Foundations for Physical Rehabilitation. Philadelphia: Mosby 2002.

[30] Souza A. Differntial Diagnosis and Mangement for the Chiropracter. 4th ed. Boston: Jones and Barlett Publishers 2008.

[31] Hewitt JD, Glisson RR, Guilak F, Vail TP. The mechanical properties of the human hip capsule ligaments. J Arthroplasty 2002; 17 (1): 1491-8.

[32] Williams PL, Bannister LH, Berry MM, Eds. Grays' Anatomy. 38th ed. Melbourne : Churchill Livingstone 1995.

[33] Peterson KF, Kendall ME, Provance PG, McIntyre Rodgers M, Romani WA. Muscles: Testing and Function with Posture and Pain. 5th ed. Philadelphia: Lippincott, Williams and Wilkins 2005.

[34] Dugailly P, Brassinne PM, Pirotte E, Mouraux E, Feipel D, Klein V. Isokinetic assessment of hip muscle concentric strength in normal subjects: A reproducibility study. Isokinetics and Exercise Science 2005; 13: 129-137.

[35] Lee D. The Pelvic Girdle. An Approach to the examination and treatment of the lumbopelvic-hip region. $3^{\text {rd }}$ ed. Melbourne: Churchill Livingstone 2004.

[36] Malliaras A, Hogan P, Nawrocki A, Crossley A, Schache K. Hip flexibility and strength measures:reliability and assocation with athletic groin pain. Br J Sports Med 2009; 43(10): 739-44.

[37] Butler D. The sensitive nervous system. Unley: Noigroup Publications 2000.

[38] Maitland GD, Hengeveld E, Banks K, English K, Eds. Vertebral Manipulation. $6^{\text {th }}$ ed. Oxford : Butterworth Heinmann 2001.

[39] Heneveld E. Banks K, Eds. Maitland's Peripheral Manipulation. Philadelphia: Elsevier Butterworth Heinmann 2005.

[40] Friberg O. Clinical symptoms and biomechanics of lumbar spine and hip joint in leg length inequality. Spine 1983; 8 (6): 643-51.

[41] Brady RJ, Dean JB, Skinner TM, Gross MT. Limb length inequality: clinical implications for assessment and intervention. J Orthop Sports Phys Ther 2003; 33: 221-34.

[42] Nicholas SJ, Tyler TF. Adductor muscle strains in sport. Sports Med 2002; 32 (5): 339-44.

[43] Tyler T, Nicholas S, Campbell R, Donellan S, McHugh M. The effectiveness of a preseason exercise program to prevent adductor muscle strains in professional ice hockey players. Am J Sports Med 2002; 30: 680-3

[44] Holmich P, Uhrskou P, Ulnits L et al. Effectiveness of active physical training as treatment for long-standing adductor-related groin pain in athletes:randomised trial. Lancet 1999; 353: 439-43.

[45] Holmich P. Exercise rehabilitation for chronic groin pain in athletes. Int Sports Med J 2000; 1 (1): 1-5.

[46] Johnston CAM, Lindsay DM, Wiley JP. Treatment of iliopsoas syndrome with a hip rotation strengthening program: a retroscpective case series. J Orthop Sports Phys Ther 1999; 29 (4): 218-24.
[47] Johnston C, Wiley J, Lindsay D, Wiseman D. Iliopsoas bursitis and tendinitis. A review. Sports Med 1998; 25 (4): 271-83.

[48] Jansen JACG, Mens JMA, Backx FJG, Stam HJ. Diagnostics in athletes with long-standing groin pain. Scan J Med Sci Sports 2008; 18: 679-90.

[49] Choi H, McCartney M, Best TM. Treatment of osteitis pubis and osteomyelitis of the pubic symphysis in athletes: a systematic review. Br J Sports Med [serial on the internet]. 2008. [About 15 screens] Available from: http://bjsm.bmj.com/content/early/2008/ 09/30/bjsm.2008.050989

[50] Gilmore O. Gilmore's groin - ten years experience of groin disruption. Sports Med Soft Tissue Trauma 1992;3(3): 12-4.

[51] Konin JG, Nofsinger CC. Physical therapy management of athletic injuries of the hip. Oper Tech Sports Med 2007; 15: 204-16.

[52] Keogh MJ, Batt ME. A review of femoroacetabular impingement in athletes. Sports Med 2008, 38 (10): 863-78.

[53] Jacobs CA, Christensen CP, Berend ME. Sport activity after total hip arthroplasty: changes in surgical technique, implant design, and rehabilitation. J Sport Rehab 2009; 18: 47-59.

[54] Stalzer S, Wahoff M, Scanlan M. Rehabilitation following hip arthroscopy. Clin Sports Med 2006; 25: 337-57.

[55] Philippon MJ, Christensen JC, Wahoff MS. Rehabilitation after arthroscopic repair of intra-articular disorders of the hip in a professional football athlete. J Sport Rehab 2009; 18: 118-34

[56] Enseki K, Robroy M, Draovitch P, Philippon M, Schenker M. The hip joint: athroscopic procedures and post operative rehabilitation. J Orthop Sports Phys Ther 2006; 36 (7): 516-25.

[57] Westby MD, Kennedy D, Carr S, Brander V, Bell M, Backman C. Post-acute physiotherapy for primary total hip arthroplasty. Cochrane Database Syst Rev 2006, Issue 2. Art. No. CD005957. DOI:10.1002/14651858.CD005957.

[58] Wang AW, Gilbey HJ, Ackland TR. Perioperative exercise programs improve early return of ambulatory function after total hip arthroplasty: a randomised controlled trial. Am J Phys Med Rehab 2002; 81(11): 801-6.

[59] Maxey L, Magnusson J. Rehabilitation for the Postsurgical Orthopedic Patient. 2nd ed. St. Louis : Mosby 2007.

[60] Foucher KC, Hurwitz DE, Wimmer MA. Preoperative gait adaptations persist one year after surgery in clinically wellfunctionning total hip replacement patients. J Biomech 2007; 40(15): 3432-7.

[61] Jan M, Hung J, Lin J, Wang S, Liu T, Tang P. Effects of a latephase exercise program on strength, walking speed, and function after total hip replacement. Arch Phys Med Rehab 2004; 85(12): 1943-51.

[62] Trudelle-Jackson E, Smith S. Effects of a late-pahse exercise program after total hip replacement. Arch Phys Med Rehab 2004; 85(7): 1056-62.

[63] Cioppa-Mosca J, Cahill J, Cavanagh J, Corradi-Scalise D, Rudnick $\mathrm{H}$, Wolff A. Postsurgical Rehabilitation Guidelines for hte Orthopaedic Clinician. St. Louis: Mosby 2006.

[64] Yun A. Sports after total hip replacement. Clin Sports Med 2006; 25: 359-64

[65] Sharma V, Morgan P, Cheng E. Factors influencing early rehabilitation after THA. Clin Orthop Relat Res 2009; 467: 140011.

[66] Rooks DS, Huang J, Bierbaum BE, et al. Effect of preoperative exercise on measures of functional status in men and women undergoing total hip and knee arthroplasty. Arthritis Rheum 2006; 55 (5): 700-8.

[67] Cibulka M, Delitto A. A comparison of two different methods to treat hip pain in runners. J Orthop Sports Phys Ther 1993; 17(4): $172-6$.

[68] Conneely M, O'Sullivan K, Edmondston S. Dissection of gluteus maximus and medius with respect to their suggested roles in pelvic and hip stability:implications for rehabilitation. Phys Ther Sport 2006; 7: 171-80.

[69] Jae-Seop OH, Heon-Seock C, Jong-Hyuk W, Oh-Yun K, ChungHwi Y. Effects of performing an abdominal drawing-in maneuver during prone hip extension exercises on hip and back extensor muscle activity and amount of anterior pelvic tilt. J Orthop Sports Phys Ther 2007; 37(6): 320-4.

[70] Bolgla L, Uhl T. Electromyographic analysis of hip rehabilitation exercises in a group of healthy subjects. J Orthop Sports Phys Ther 2005; 35(8): 487-94. 
[71] Synder K. Resistance training is accompanied by increases in hip strength and changes in lower extremity biomechanics during running. Clin Biomech 2009; 24: 26-34.

[72] O'Sullivan PB, Twomey LT, Allison GT. Evaluation of specific stabilizing exercise in the treatment of chronic low back pain with radiologic diagnosis of spondylolysis or spondylolisthesis. Spine 1997; 22 (24): 2959-67.

[73] Richardson CA, Jull GA. Muscle control - pain control. What exercises would you prescribe? Man Ther 1995; 1: 2-10.

[74] Cowan SM, Schache AG, Brukner P, et al. Delayed onset of Transversus Abdominus in long-standing groin pain. Med Sci Sports Exerc 2004; 36 (12): 2040-5.

[75] Cusi MF, Juska-Butel CJ, Garlick D, Argyrous G. Lumbopelvic stability and injury profile in rugby union players. NZJ Sports Med 2000; 29 (1): 14-8.
[76] Makofsky H, Panicker S, Abbruzzese J, et al. Immediate effect of grade iv inferior hip joint mobilisation on hip abductor torque: a pilot study. J Man Manip Ther 2007; 15 (2): 103-11.

[77] Yerys S, Makofsky H, Byrd C, Pennachio J, Cinkay J. Effect of mobilization of the anterior hip capsule on gluteus maximus strength. J Man Manip Ther 2002; 10 (4): 218-24.

[78] Wong C, Schauer-Alvarez C. Effect of strain counterstrain on pain and strength in hip musculature. J Man Manip Ther 2004; 12 (4): 215-23.

[79] Shrier I. Does stretching improve performance? A systematic and critical review of the literature. Clin J Sport Med 2004; 14 (5): 26773.

[80] Verrall GM, Slavotinek JP, Barnes PG, Esterman A, Oakeshott RD, Spriggins AJ. Hip joint range of motion restriction precedes athletic chronic groin injury. J Sci Med Sport 2007; 10 (6): 463-66.

(c) Alison Quinn; Licensee Bentham Open.

This is an open access article licensed under the terms of the Creative Commons Attribution Non-Commercial License (http://creativecommons.org/licenses/by-nc/3.0/) which permits unrestricted, non-commercial use, distribution and reproduction in any medium, provided the work is properly cited. 